RASĀYAN J. Chem.

Vol. 14 | No. 2 |905-913| April - June | 2021 ISSN: 0974-1496 | e-ISSN: 0976-0083 | CODEN: RJCABP http://www.rasayanjournal.com http://www.rasayanjournal.co.in

\title{
FABRICATION OF CERITINIB COCRYSTALS WITH IMPROVED SOLUBILITY: PREPARATION, SOLID-STATE CHARACTERIZATION, SOLUBILITY STUDIES, AND MOLECULAR DOCKING STUDIES
}

\author{
Ankit Awasthi ${ }^{1}$, H. M. Dheeraj ${ }^{1}$, Sumit Birangal ${ }^{2}$, Aravind Pai $^{2}$, Girish Pai ${ }^{3}$ \\ and Muddukrishna Badamane Sathyanarayana ${ }^{1, \bigotimes}$ \\ ${ }^{1}$ Department of Pharmaceutical Quality Assurance, Manipal College of Pharmaceutical Sciences, \\ Manipal Academy of Higher Education, Manipal-576104, Karnataka, INDIA. \\ ${ }^{2}$ Department of Pharmaceutical Chemistry, Manipal College of Pharmaceutical Sciences, \\ Manipal Academy of Higher Education, Manipal-576104, Karnataka, INDIA \\ ${ }^{3}$ Department of Pharmaceutics, Manipal College of Pharmaceutical Sciences, Manipal Academy \\ of Higher Education, Manipal-576104, Karnataka, INDIA \\ ${ }^{\square}$ Corresponding Author: krishna.mbs@manipal.edu
}

\begin{abstract}
In the current research work, a new co-crystal of ceritinib with nicotinamide and quercetin hydrate was prepared with increased solubility. Ceritinib belongs to BCS class IV drug which having poor permeability and low aqueous solubility that leads to poor oral bioavailability. Thus, an endeavor has been made by the co-crystal technique to increase its solubility. Pharmaceutical co-crystals are also called multi-component crystals having a definite stoichiometric ratio of active pharmaceutical ingredients (APIs) and coformers and they are joined by noncovalent interactions such as hydrogen bonds, $\pi-\pi$ packing, and Vander Waals forces. In current research work based on hydrogen bond formation the coformer selected were Nicotinamide and Quercetin Hydrate. The three ratios (1: 1, 1: 2 and 2:1) of cocrystals of ceritinib with nicotinamide were prepared by the dry grinding method. The confirmation of formation of cocrystals was confirmed y powder X-ray diffractometry (PXRD), differential scanning calorimetry (DSC) and Fourier transform (FT) IR. Based on the saturation solubility studies, it obvious that the solubility of ceritinib with Nicotinamide was on the higher side as compare to Quercetin hydrate cocrystals and pure ceritinib The increase in solubility of cocrystals with Nicotinamide in ratios $(1: 1,1: 2$ and 2: 1$)$ increased by $(119,155.3,83.1)$ fold as compared to Pure Ceritinib
\end{abstract}

Keywords: Ceritinib, Solid-state Characterization, Quercetin Hydrate, Cocrystals, HPLC, Hydrogen Bonding, Saturated Solubility, Nicotinamide

RASĀYAN J. Chem., Vol. 14, No.2, 2021

\section{INTRODUCTION}

Ceritinib has the potential for the treatment of ALK-positive metastatic NSCLC (non-little cell lung cancer) which belongs to the second era of ALK (anaplastic lymphoma kinase) inhibitor. ${ }^{1}$ It is manufactured and marketed under the trade name of zykadia by Novartis. On Apr 7, 2014 zykadia was approved by USFDA. Ceritinib is sold as $150 \mathrm{mg}$ strength hard gelatin capsule with a maximum daily dose of $750 \mathrm{mg} .{ }^{2}$ As per BCS classification, Ceritinib Belongs to Class IV drug which has the issue of low solubility and low permeability which will result in poor oral bioavailability. Its solubility in aqueous media is $\mathrm{pH}$-dependent it has good solubility at low $\mathrm{pH}$ values and poor solubility at neutral $\mathrm{pH}$ values. ${ }^{3}$ Ceritinib is a substrate for apical efflux transporter and glycoprotein. The highest concentrations were achieved after about 4 to 6 hours following oral administration of ceritinib. The terminal half-life is 41 hours. $^{2}$ Various attempts are made to increase aqueous solubility by co amorphous techniques after a lot of literature surveys it was found that previously there was no attempt made by a co-crystallization technique using a suitable coformer. cocrystals are the most stable form.it increases solubility by the formation of hydrogen bonds with drug and coformer. ${ }^{4}$ Flavonoids have also not been explored as coformers to form cocrystals with ceritinib. Flavonoids have a wide range of uses and also can be used for synergistic effect also flavonoids are

Rasayan J. Chem., 14(2), 905-913(2021)

http://dx.doi.org/10.31788/ RJC.2021.1426244

This work is licensed under a CC BY 4.0 license. 
RASĀYAN J. Chem.

Vol. 14 | No. 2 |905-913| April - June | 2021

endogenous to the human body as they are present in our diet hence are preferred coformers The main advantage of flavonoids in cocrystal technology is mainly ease of hydrogen bonding favors solubility This current research work is aimed at enhancing the aqueous solubility of ceritinib cocrystals by crystal engineering technology which directly helps in reduction of dose and overall cost of healthcare. Cocrystals are considered novel and therefore can be patented. ${ }^{6}$ Any pharmaceutical Cocrystal claiming to be patented must be novel, non-obvious and helpful. As solvates and hydrates can claim patentability, Cocrystals is considered as patentable inventions. The co-crystallization strategy can be utilized as one of the strategies because of its commercial feasibility and for non-ionizable drugs, it can also increase the diversity of solidstate form of drug and change pharmaceutical properties by adjustment of stability, mechanical behavior solubility, dissolution rate and bioavailability. By utilizing the approach of creating cocrystals of ceritinib with suitable coformers there is a chance to increase the solubility and or permeability and API resulting in novel dosage forms which can be patented also The objective of the current research work is to make ceritinib cocrystals by utilizing suitable coformer which includes Nicotinamide and Quercetin hydrate and affirmation by solid-state characterization (FTIR, DSC and XRD) and HPLC method can be used for analyzing the increased solubility of the prepared cocrystals. ${ }^{5,7,8}$<smiles>Cc1cc(Nc2ncc(Cl)c(Nc3ccccc3S(=O)(=O)C(C)C)n2)c(OC(C)C)cc1C1CCNCC1</smiles>

Fig.-1: Structure of Ceritinib, Nicotinamide, and Quercetin hydrate ${ }^{9,10,11}$

\section{Materials}

\section{EXPERIMENTAL}

Ceritinib was procured from Hetro Pharma, Hyderabad. Quercetin hydrate and Nicotinamide were procured from Sigma- Aldrich. Acetonitrile (HPLC Grade), methanol was procured by Finar chemicals Ahmedabad. Dipotassium hydrogen phosphate was procured from Merck life science private Limited. Siemens ultrawater purification system was used to obtain HPLC grade water for an experiment in Lab.

\section{Selection of Coformer}

During the Selection of coformer primary difficulty is coformer choice that fits with API. There are different methods available such as the supramolecular synthon approach, Cambridge structural database and Hansen Solubility parameter for co-crystal screening. The supramolecular synthon approach is used in current research work for coformer determination which includes various stages-

1. Selection of target

2. Information of Hydrogen bonding of API and coformer to find a complementary functional group of API which is capable for hydrogen bond formation. ${ }^{8}$

There are 3 hydrogen bond contributors and 8 hydrogen bond acceptors present in ceritinib which is the target molecule. There are 1 hydrogen bond contributor and 2 hydrogen bond acceptors present in nicotinamide and there are 5 hydrogen bond contributors and 7 hydrogen acceptors present in Quercetin hydrate. Proper selection of coformer with API leads to an increase in solubility of API therefore selection of coformers plays a very important role.

\section{Preparation of Cocrystals}

Slow evaporation, slurry conversion and dry grinding like methods are used for Cocrystals formation ${ }^{(12) .}$ In this research work preparation of cocrystals was done in molar proportions 1:1, 1:2, 2:1 of ceritinib and Nicotinamide and Quercetin hydrate respectively through dry grinding method. Necessary Amounts of Ceritinib, Nicotinamide and Quercetin hydrate are weighed and triturate with fixed speed for 10 mins with the help of motor and pestle. A later collection of co-crystals was done for further analysis. The 1:1 molar proportions of physical mixture samples were also prepared. 
RASĀYAN J. Chem.

Vol. 14 | No. 2 |905-913| April - June | 2021

Table-1(A): Mass needed for the Preparation of Ceritinib: Nicotinamide Co-crystals in Specific Ratios

\begin{tabular}{c|c|c|c}
\hline Ceritinib: Nicotinamide ratio & Ceritinib $(\mathrm{mg})$ & Nicotinamide $(\mathrm{mg})$ & Batch Size \\
\hline $1: 1$ & 82.04 & 17.95 & $100 \mathrm{mg}$ \\
\hline $1: 2$ & 69.55 & 30.44 & $100 \mathrm{mg}$ \\
\hline $2: 1$ & 90.138 & 9.86 & $100 \mathrm{mg}$ \\
\hline $1: 1$ Physical mix & 82.04 & 17.95 & $100 \mathrm{mg}$ \\
\hline
\end{tabular}

Table-1(B): Mass needed for the Preparation of Ceritinib-Quercetin hydrate Co-crystals in Specific Ratios

\begin{tabular}{c|c|c|c}
\hline Ceritinib: Quercetin hydrate ratio & Ceritinib $(\mathrm{mg})$ & Quercetin hydrate $(\mathrm{mg})$ & Batch size \\
\hline $1: 1$ & 64.87 & 35.12 & $100 \mathrm{mg}$ \\
\hline $1: 2$ & 48.01 & 51.98 & $100 \mathrm{mg}$ \\
\hline $2: 1$ & 78.69 & 21.30 & $100 \mathrm{mg}$ \\
\hline $1: 1$ Physical mix & 64.87 & 35.12 & $100 \mathrm{mg}$ \\
\hline
\end{tabular}

\section{Solid-State Characterization Studies}

The Spectra of Physical mixture, co-crystals, pure ceritinib was obtained with the help of Shimadzu FTIR: 8300 system (Kyoto, Japan). Over a range of $4000-500 \mathrm{~cm}^{-1}$ (Twenty five scans resolution $4 \mathrm{~cm}^{-1}$ ) the IR spectrum was taken. For the preparation of disc disperse the sample in $\mathrm{KBr}$ followed by grinding in a fixed amount of pressure (1000 psig).

\section{DSC}

Thermal analysis is carried out with the assistance of Shimadzu TA: 60WS thermal analyzer. in aluminum pans (0.1 mm thickness) necessary amount of sample (Approx. $5 \mathrm{mg}$ ) was taken then cover with an aluminum lid. At temperature $25-300^{\circ} \mathrm{C}$, the test sample run is carried out with $10^{\circ} \mathrm{C} / \mathrm{min}$ increase in temperature. And then analysis of pure API, coformer, (1:1) Physical mixture, formed co-crystals was carried out.

\section{XRD}

X-ray powder diffraction pattern is obtained using Rigakuminiflex $600 \mathrm{X}$-ray diffractometer (Rigaku Co., Tokyo, Japan) powered at $600 \mathrm{~W}$ (X-ray tube) with a fixed tube current $(15 \mathrm{~mA})$ and a fixed voltage (40 $\mathrm{kV})$. A graphite monochromator is utilized to detect $\mathrm{x}$-ray beam monochomation, and a typical scintillation counter is used. Diffraction intensities were calculated in 5-80 ${ }^{\circ}(2 \theta)$ range.

\section{Saturated Solubility Studies}

API solubility prepared cocrystals of ceritinib, and physical mixture is calculated by the shake-flask process. IP phosphate buffer $\mathrm{pH} 6.8$ is used as a solvent because it mimics the $\mathrm{pH}$ of the intestine Excess amounts of each sample were weighed and applied to $2 \mathrm{ml}$ of the selected solvent scheme, exceeding their aqueous solubility to prepare a saturated solution. All the samples are then shaken in an orbital shaker, holding at $100 \mathrm{rpm}$ the temperature of $37^{\circ} \mathrm{C}$. Samples are obtained after $24 \mathrm{hrs}$, and then centrifugation at 10,000 RPM. Separate and dilute the clear supernatant solution and then inject the sample into the HPLC system to fall in the calibration range before injection into the HPLC system using the HPLC process. The samples were quantified with a PDA detector using an established HPLC process. ${ }^{13-15}$

\section{HPLC Method}

Shimadzu LC-10 series HPLC (Shimadzu Corporation, Kyoto, Japan) was used to analyze Ceritinib, physical mixtures and prepared ceritinib cocrystals. The system consists of an SCL-10A VP controller unit, an LC-20AD quaternary gradient pump, a DGU-20A5 degasser unit, a SIL20AC HT refrigerated autosampler, the detector of model SPD-M10AVP PDA. The buffer solution was filtered using a $0.45 \mu \mathrm{m}$ filter with the help of a glass vacuum-filtration. Equitron ultrasonic bath is used for degassing the mobile phase. Gracemart $\mathrm{C}_{18}(250 \mathrm{~mm} \times 4.6 \mathrm{~mm} \times 5 \mu \mathrm{m})$ column was used with mobile phase composition of acetonitrile and phosphate buffer $(25 \mathrm{mmol}) \mathrm{pH}$ adjusted to 3.2 (with $10 \%$ orthophosphoric acid) in the proportion of $50: 50 \mathrm{v} / \mathrm{v}$. The flow rate was set to $1.0 \mathrm{ml} / \mathrm{min}$, column oven temperature $35^{\circ} \mathrm{c}$ was maintained. The detection was carried at a wavelength of $276 \mathrm{~nm}$ using a PDA detector. 
RASĀYAN J. Chem.

Vol. 14 | No. 2 |905-913| April - June | 2021

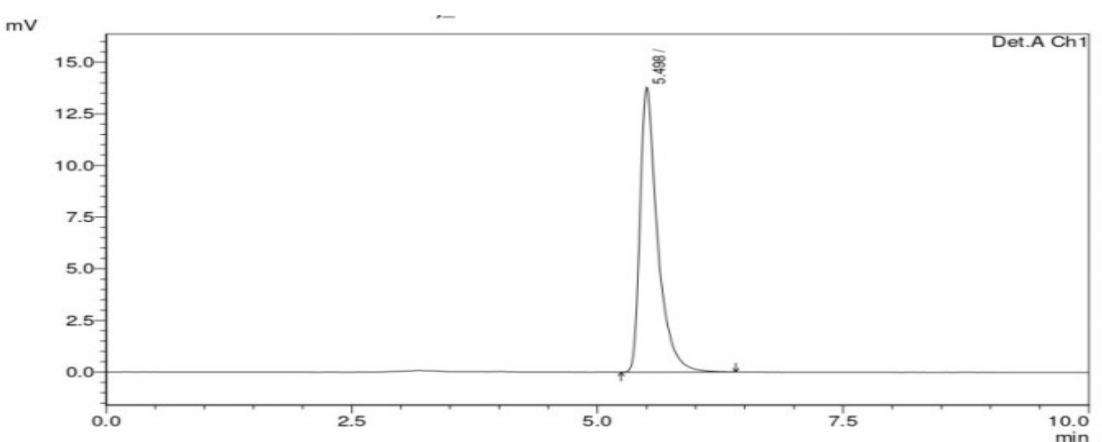

Fig.-2: Chromatogram of ceritinib API developed using optimized HPLC Method

\section{Molecular Docking Studies}

Schrodinger design suites with Maestro 10.4 interface are used for all kinds of molecular docking simulations. With the help of a 2D sketch, all the structures were drawn and they can be converted into 3D. Ligprep was used for ligand preparation; various coformers, ionization states at the given $\mathrm{pH}$ range can be generated with the help of Ligprep. A flexible ligand alignment option is used for the joining of prepared ligands. Protein data bank (PDB CODE: (4MK) is used for obtaining protein. With the help of the protein preparation wizard tool, the raw protein was processed. this component will convert selenomethionines to methionine, neutralizes the side chain and add hydrogen. PRIME is utilized for filling missing residues. Finally, energy is minimized, and protein was refined. Then the protein which is prepared can be used for molecular docking. Ligand docking and GRID generation are two-step processes for Docking. Grid box is created in the first stage and then at active sites docking of the ligand is carried out. Superimposing the crystal ligand structures is used for internal validation of docking poses. RMSD should be less than 2. For more accurate results extra precision docking tools can be used. Based on the Glide score, Docking score, Glide E model score the docking result analyzed. ${ }^{16}$

\section{Solid-State Characterization}

\section{RESULTS AND DISCUSSION}

\section{FTIR}

The FTIR spectra of CER-N 1:1 Fig.-3(B) batch revealed that cocrystals were formed as spectra were similar with less intensity $1377 \mathrm{~cm}^{-1} \mathrm{CN}$ stretching is absent in cocrystals and there is peak is seen at $3361 \mathrm{~cm}^{-1}$ for NH stretching in cocrystals as compare to pure drug Fig.-3(A). The FTIR spectra of the CERQ 1:1 Fig.-3(C) batch revealed that cocrystals were formed as spectra were different for pure and cocrystals. In cocrystals, we find spectra at $1665 \mathrm{~cm}^{-1}$ with a sharp peak which shows $\mathrm{c}=\mathrm{O}$ of Quercetin is interacting with $\mathrm{NH}$ of piperidine of ceritinib which shows $\mathrm{H}$ bonding interaction. This is different from pure drug Fig.-3(A).

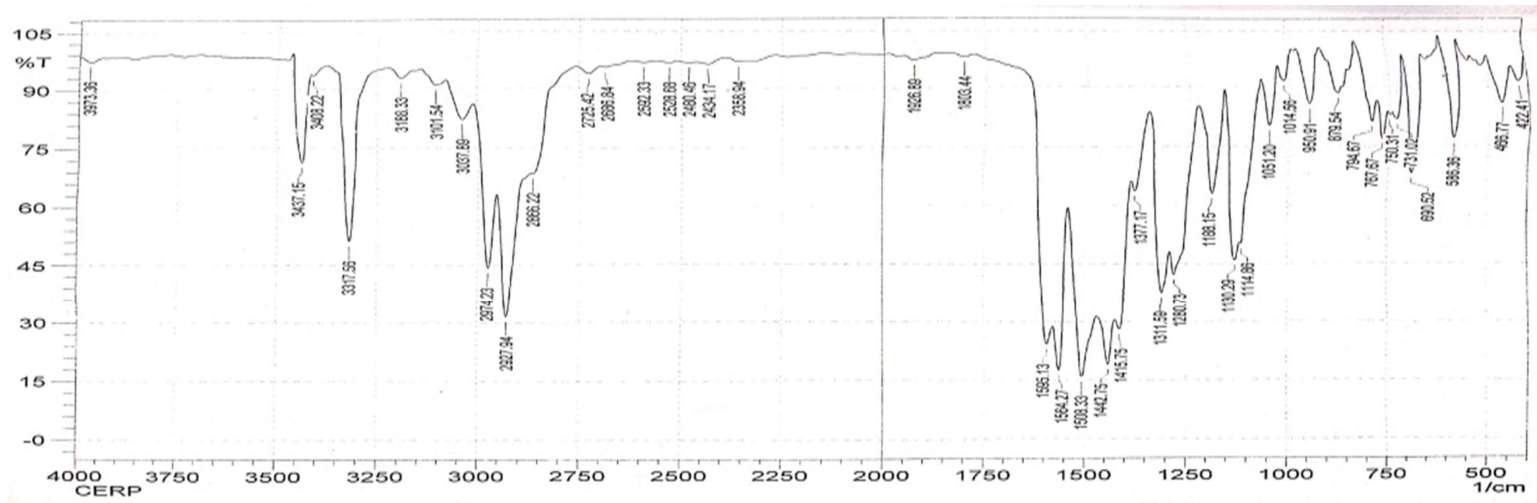

\section{DSC}

Fig.-3(A): FTIR Spectra of ceritinib API

In Fig.-4(A) the DSC results of pure Ceritinib, Nicotinamide. Ceritinib- Nicotinamide prepared in (1:1, $1: 2,2: 1)$ molar ratio by dry grinding method and $1: 1$ ratio physical mixture. The melting pattern difference 908 
RASĀYAN J. Chem.

Vol. 14 | No. 2 |905-913| April - June | 2021

of cocrystals was seen when compared to Ceritinib pure $\left(181.30^{\circ} \mathrm{C}\right)$. The ceritinib and Nicotinamide cocrystals batch of $1: 1$ show an endothermic peak at $131.02{ }^{\circ} \mathrm{C}$ and $160.08^{\circ} \mathrm{C}$ and cocrystals batches of 1:2 show an endothermic peak at $128.99^{\circ} \mathrm{C}$ and $152.88^{\circ} \mathrm{C}$ and cocrystals batches of $2: 1$ show an endothermic peak at $129.45^{\circ} \mathrm{C}$ and $164.09^{\circ} \mathrm{C}$ respectively which is slightly different from pure ceritinib and Nicotinamide at $181.30^{\circ} \mathrm{C}$ and $137.60^{\circ} \mathrm{C}$ respectively.

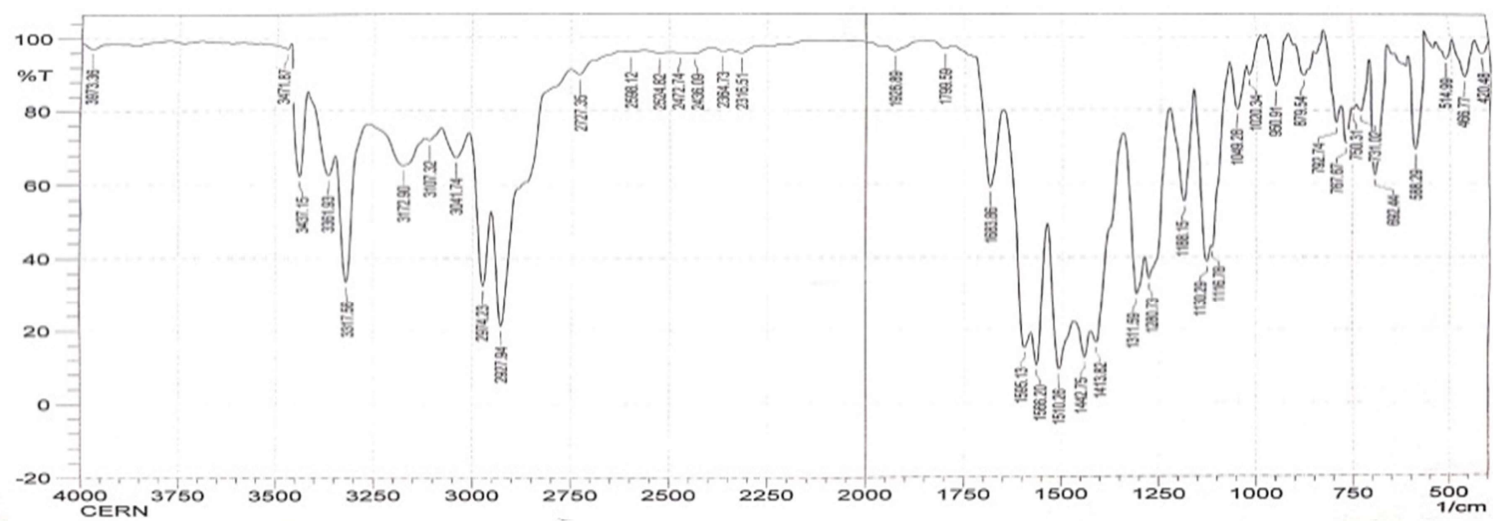

Fig.-3(B): FTIR Spectra of ceritinib Nicotinamide Cocrystals (1:1)

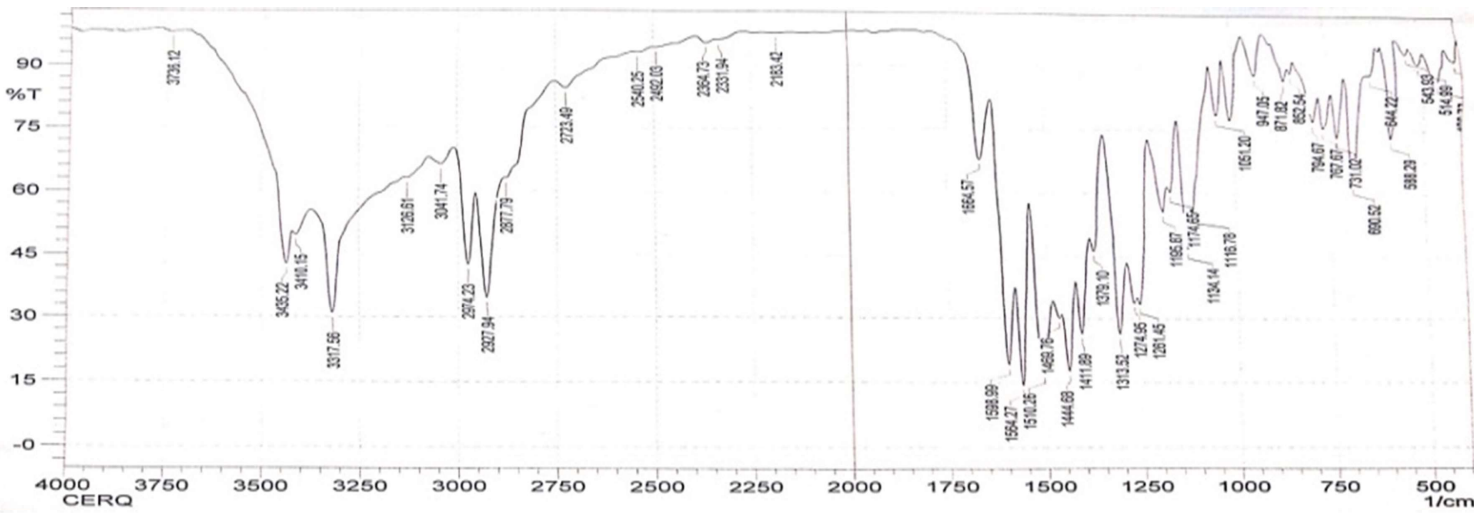

Fig.-3(C): FTIR Spectra of Ceritinib-Quercetin hydrate (1:1)

In Fig.-4(B) the DSC result of pure Ceritinib, Quercetin Hydrate, Ceritinib- Quercetin Hydrate prepared in $(1: 1,1: 2,2: 1)$ molar ratio by dry grinding method and $1: 1$ ratio physical mixture. The melting pattern difference of cocrystals was seen when compared to Ceritinib pure $\left(181.30^{\circ} \mathrm{C}\right)$.

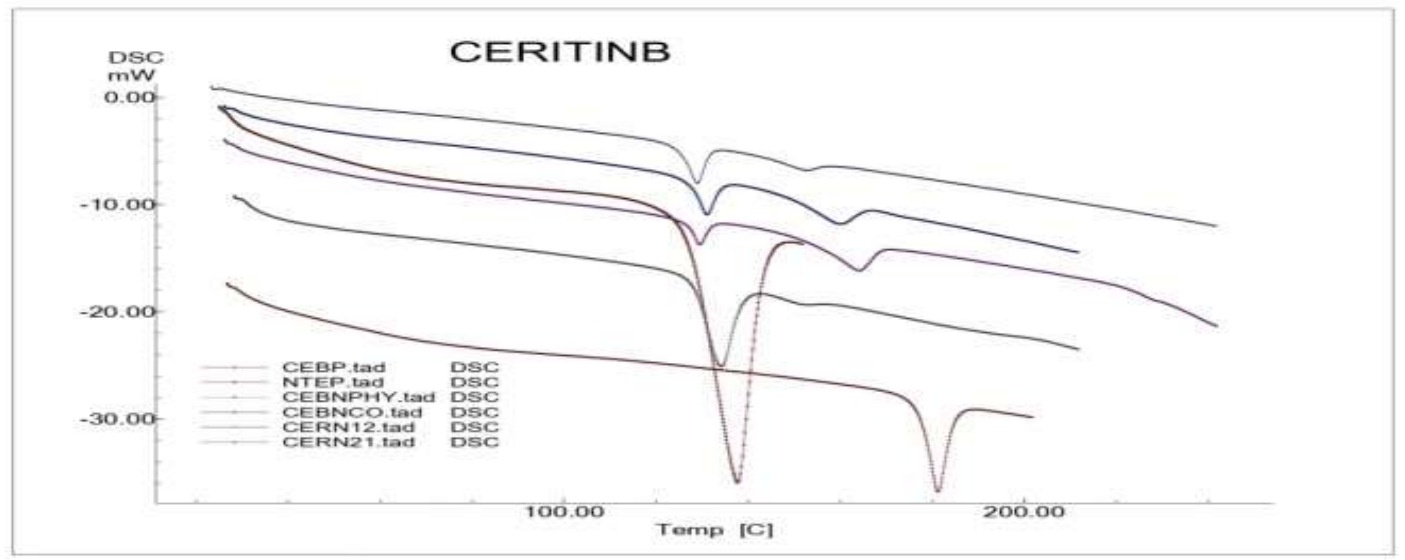

Fig.-4(A): DSC Thermograms CEBP: Ceritinib Pure Drug; NTEP:Nicotinmide Pure Drug; CEBNPHY:CeritinibNicotinamide Physical mixture, CEBNCO:Ceritinib-Nicotinamide CC(1:1); CEBN(1:2): Ceritinib-Nicotinamide $\mathrm{CC}(1: 2) ; \operatorname{CEBN}(2: 1)$ : Ceritinib-Nicotinamide $\mathrm{CC}(2: 1)$ 
RASĀYAN J. Chem.

Vol. 14 | No. 2 |905-913| April - June | 2021

The ceritinib and Quercetin Hydrate cocrystals batch of $1: 1$ show endothermic peak at $168.04{ }^{\circ} \mathrm{C}$ and $316.20^{\circ} \mathrm{C}$ and cocrystals batches of $1: 2$ show an endothermic peak at $129.91{ }^{\circ} \mathrm{C}$ and $167.09{ }^{\circ} \mathrm{C}$ and cocrystals batches of $2: 1$ show an endothermic peak at $169.67{ }^{\circ} \mathrm{C}$ and $229.12{ }^{\circ} \mathrm{C}$ respectively which is slightly different from pure ceritinib and Quercetin Hydrate at $181.30^{\circ} \mathrm{C}$ and $288.12{ }^{\circ} \mathrm{C}$ respectively. Thus it was concluded that there is significant interaction between Ceritinib, Quercetin Hydrate and Nicotinamide used for cocrystal preparation.

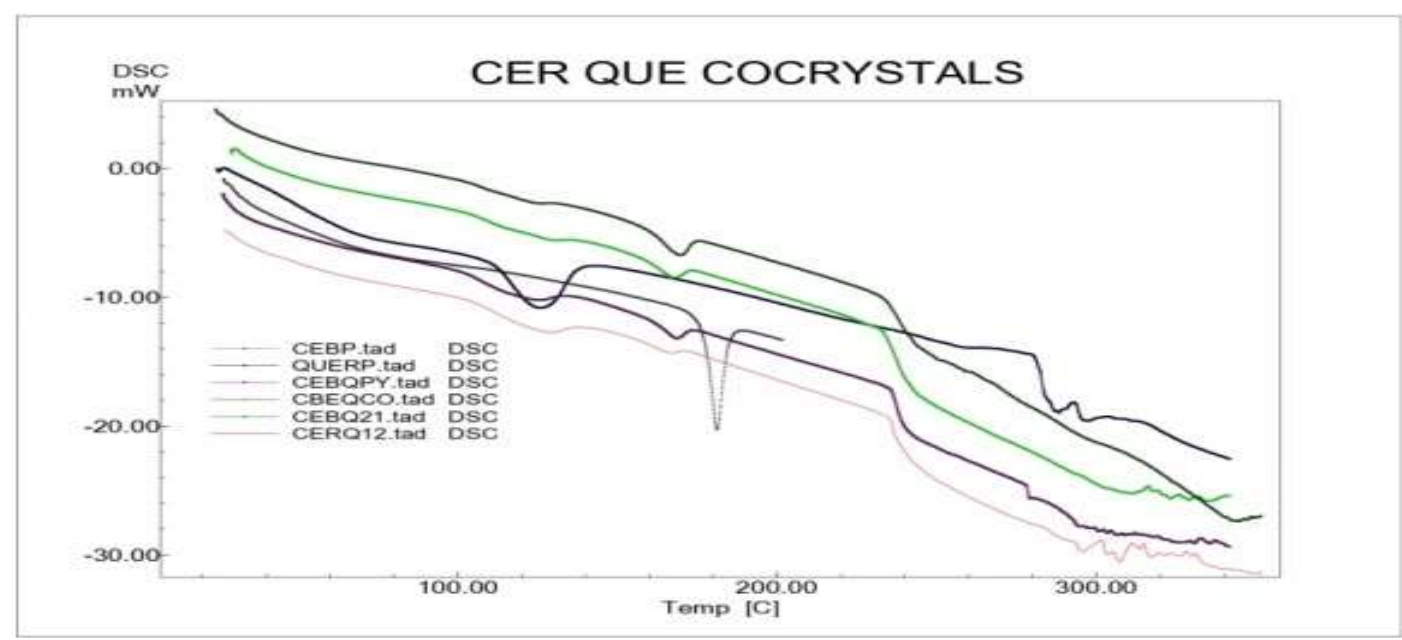

Fig.-4(B): DSC Thermograms CEBP: Ceritinib Pure Drug,QUEP:Quercetin Pure Drug; CEBQPHY:CeritinibQuercetin Physical Mixture,CEBQCO: Ceritinib-Quercetin CC(1:1), CEBQ(1:2)Ceritinib-Quercetin CC(1:2),CEBQ(2:1):Ceritinib-Nicotinamide CC(2:1)

Table-2: DSC Thermogram Melting Point Values for Pure Drug, Pure Coformers and Cocrystal (CC) Batches

\begin{tabular}{c|c}
\hline Sample & Melting Endotherm $\left({ }^{\circ} \mathrm{C}\right)$ \\
\hline CEB API & $181.30{ }^{\circ} \mathrm{C}$ \\
\hline NICOTINAMIDE & $137.60{ }^{\circ} \mathrm{C}$ \\
\hline QUERCETIN & $288.12^{\circ} \mathrm{C}$ \\
\hline CEBNPM & $134.1{ }^{\circ} \mathrm{C}$ \\
\hline CEBN11 & $131.02{ }^{\circ} \mathrm{C}$ and $160.08{ }^{\circ} \mathrm{C}$ \\
\hline CEBN12 & $128.99^{\circ} \mathrm{C}$ and $152.88^{\circ} \mathrm{C}$ \\
\hline CEBN21 & $129.45^{\circ} \mathrm{C}$ and $164.09{ }^{\circ} \mathrm{C}$ \\
\hline CEBQPM & $168.777^{\circ} \mathrm{C}$ and $277.76{ }^{\circ} \mathrm{C}$ \\
\hline CEBQ11 & $168.04{ }^{\circ} \mathrm{C}$ and $316.20^{\circ} \mathrm{C}$ \\
\hline CEBQ12 & $129.91{ }^{\circ} \mathrm{C}$ and $167.09{ }^{\circ} \mathrm{C}$ \\
\hline CEBQ21 & $169.67{ }^{\circ} \mathrm{C}$ and $229.12^{\circ} \mathrm{C}$ \\
\hline
\end{tabular}
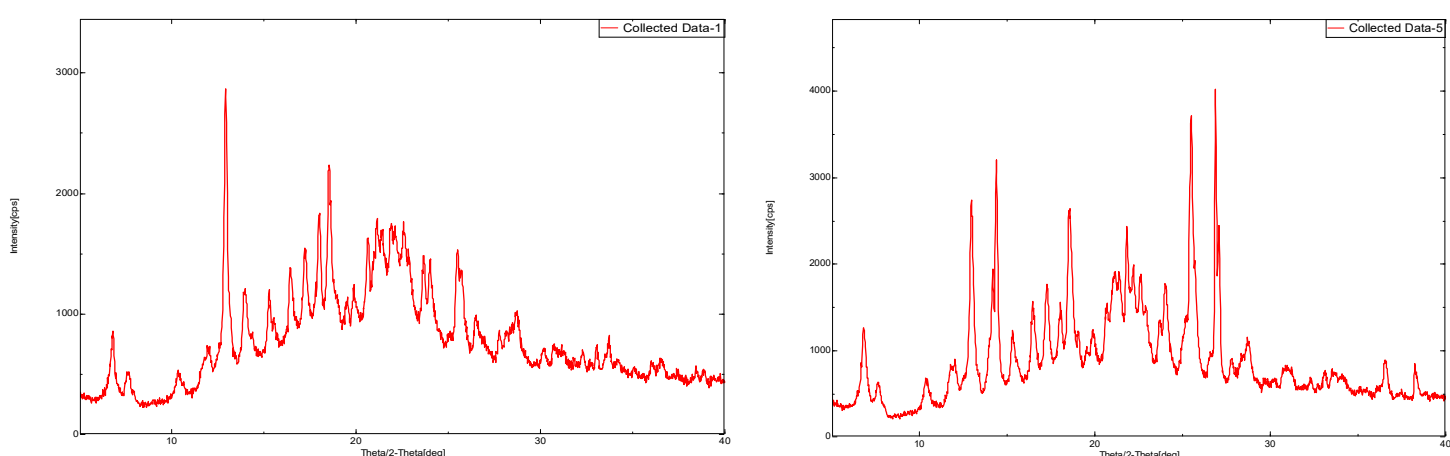

Fig.-5:(A) PXRD of ceritinib API, (B) PXRD of ceritinib with Nicotinamide of cc 1:1 
RASĀYAN J. Chem.

Vol. 14 | No. 2 |905-913| April - June | 2021

\section{XRD}

When PXRD results of pure drug, and ceritinib- Nicotinamide 1:1 cocrystals were compared, cocrystals showed a significant difference in the entire diffraction pattern. The intensity of X-rays diffraction pattern of ceritinib API at $2 \theta$ angle of 16.09 was found to be $100 \%$, whereas cocrystals of Ceritinib -Nicotinamide of $1: 1$ showed $100 \%$ at 24.43 over $2 \theta$ angle. The shift in $100 \%$ intensity is seen in comparison with pure drug is which is due to interplanar distance (d angle) indicating different arrangement of the molecule (Fig.$5 \mathrm{~A}$ and Table-3).

Table-3: XRD Results of Ceritinib API and Cocrystal

\begin{tabular}{c|c|c|c}
\hline Sample Id & $2 \theta$ (degree) & $\mathrm{d}($ angle) & Intensity \\
\hline Ceritinib & 16.09 & 5.49 & 1856.72 \\
\hline PM (CERN) & 54.44 & 1.68 & 2304.06 \\
\hline CERN $(1: 1)$ & 24.43 & 2.38 & 1043.1 \\
\hline
\end{tabular}

\section{Saturated Solubility Studies}

Solubility studies are done, and samples are taken after $24 \mathrm{hr}$. for analyzing the solubility of the pure drug and prepared crystals batches. There were analyzed by using optimized HPLC. Table- 4 shows the saturation solubility data. Ceritinib pure saturation solubility in phosphate buffer ( $\mathrm{pH}$ 6.80) IP was found to be 1.642 $\mathrm{ug} / \mathrm{ml}$ after 24 hours at temperature $37^{\circ} \mathrm{C}$. Whereas the co-crystal form of Ceritinib with Nicotinamide in the ratio 1:1, 1:2 and 2:1 is provided by Dry Grinding Method showing dynamic solubility of $195.4 \mathrm{ug} /$ $\mathrm{mL}, 254.9 \mathrm{ug} / \mathrm{mL}$ and $136.4 \mathrm{ug} / \mathrm{ml}$ in phosphate buffer (pH-6.80) IP after 24 hours, at temperature $37{ }^{\circ} \mathrm{C}$ respectively. Cocrystal form of Ceritinib and Quercetin hydrate in the proportion 1:1, 1:2 and 2:1 is produced using a dry grinding method showing dynamic solubility of $21.95 \mathrm{ug} / \mathrm{ml}, 27.38 \mathrm{ug} / \mathrm{ml}$ and 13.42 $\mathrm{ug} / \mathrm{ml}$ after 24 hours in phosphate buffer $(\mathrm{pH}-6.80) \mathrm{IP}$ at $37^{\circ} \mathrm{C}$ respectively. Significant improvement was seen in the solubility of cocrystals when compared to pure drug and physical mixtures. CeritinibNicotinamide cocrystal (1:2) form shows an approximately 155.2-fold increase in solubility as compared to its pure form and physical mixture.

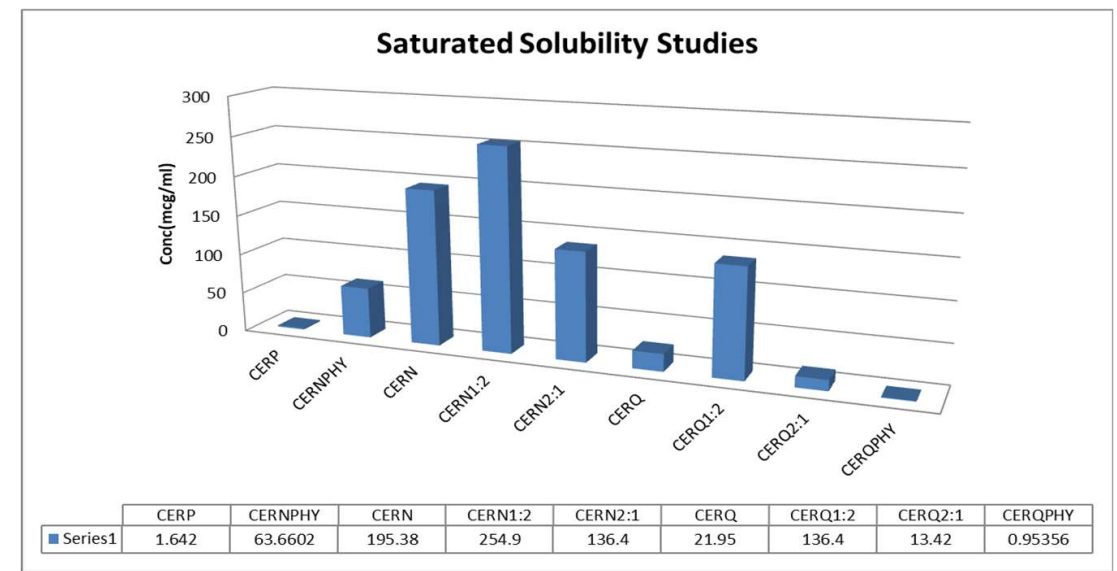

Fig.-6: Batches of Cocrystals, Pure Drug and in Phosphate Buffer pH 6.8(Saturation Solubility Studies)

\section{Molecular Docking}

The protein crystal structure, 4MKC containing Ceritinib entrapped in the protein Anaplastic lymphoma kinase was retrieved from the protein database. The amino group and pyrimidine ring of Ceritinib makes H-bond interaction with Amino acid residues MET1198. The Sulphonyl group of Ceritinib makes H-bond interaction with Amino acid residues LYS1150. $\mathrm{N}^{+} \mathrm{H}_{2}$ of piperidine ring of Ceritinib make a salt bridge with amino acid GLU1210.

Table-4: Data of Cocrystals and Pure Drug (Saturation Solubility Studies)

\begin{tabular}{c|c|c}
\hline Batch & Solubility in phosphate buffer $\mathrm{pH} 6.8(\mathrm{ug} / \mathrm{ml})$ & Fold \\
\hline CERP & 1.642 & - \\
\hline CERQPHY & 0.95356 & 0.5 \\
\hline CERNPHY & 63.6602 & 38.78 \\
\hline
\end{tabular}


RASĀYAN J. Chem.

Vol. 14 | No. 2 |905-913| April - June | 2021

\begin{tabular}{c|c|c}
\hline CERQ CC $(1: 1)$ & 21.95 & 13.37 \\
\hline CERN CC $(1: 1)$ & 195.4 & 119 \\
\hline CERN CC $(1: 2)$ & 254.9 & 155.3 \\
\hline CERN CC $(2: 1)$ & 136.4 & 83.1 \\
\hline CERQ CC $(1: 2)$ & 27.38 & 16.68 \\
\hline CERQ CC $(2: 1)$ & 13.42 & 8.175 \\
\hline
\end{tabular}

The co-crystalized form of Ceritinib with co-formers Nicotinamide binds to the protein in the same binding pocket with similar interactions and some additional interactions. $\mathrm{N}^{+} \mathrm{H}_{2}$ of piperidine ring of Ceritinib make a salt bridge with amino acid GLU1203. The docking score of ceritinib was found to be 10.012 and the co-crystalized form of Ceritinib with co-formers Nicotinamide was found to be -11.126. An increase in the docking score of the co-crystalized form of Ceritinib might be an indication of the better binding and activity of Ceritinib.
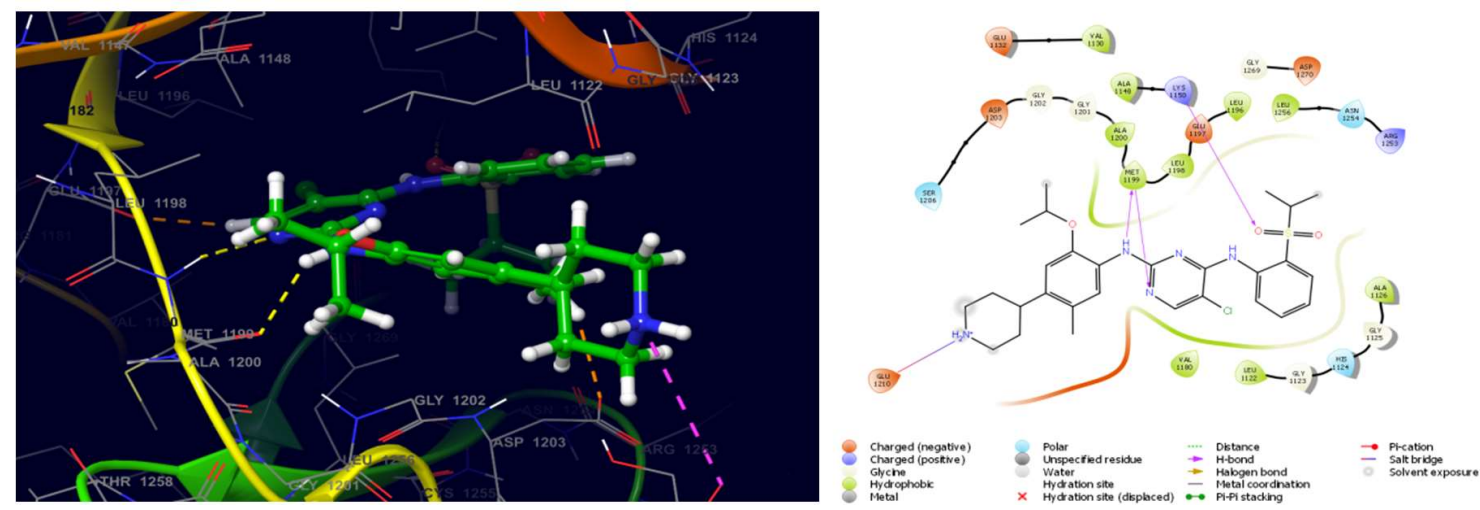

Fig.-7: 3D and 2D Interaction of Ceritinib
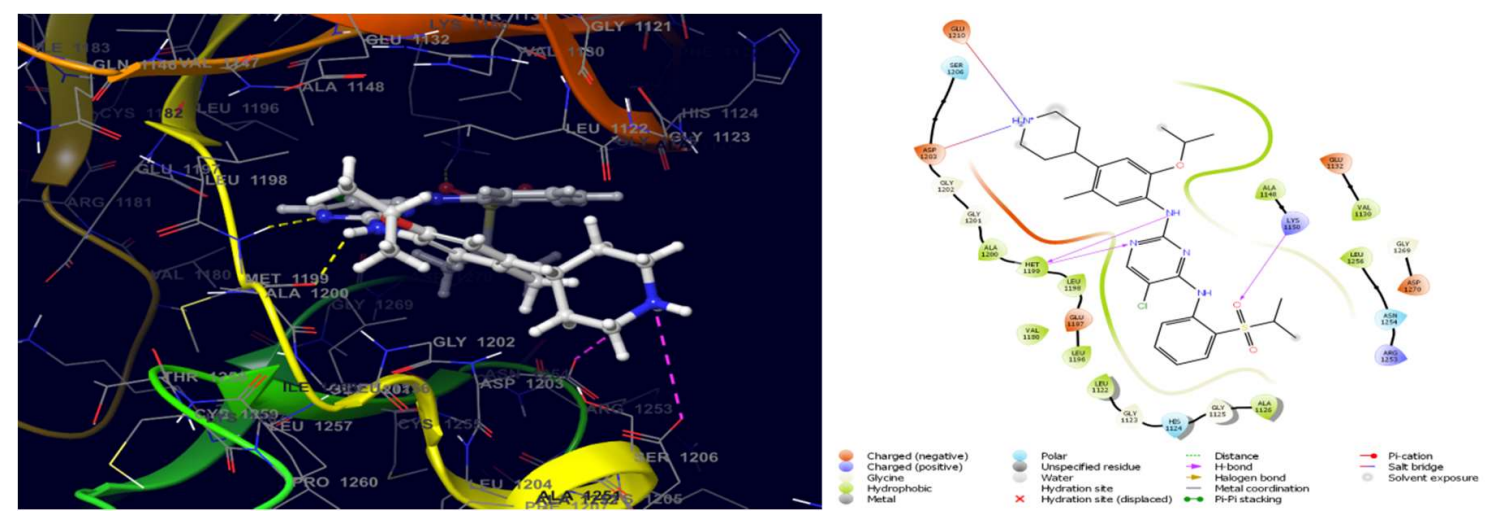

Fig.-8: 3D and 2D Interaction of Ceritinib with Co-former Nicotinamide

\section{CONCLUSION}

Ceritinib formed stable cocrystals with Nicotinamide and Quercetin hydrate. DSC, FTIR, XRD results proved that cocrystals have been formed. Based on the saturation solubility studies, it obvious that the solubility of ceritinib with Nicotinamide was on the higher side as compare to Quercetin hydrate cocrystals and pure ceritinib a 155.4 fold increase in solubility was achieved, further confirmed by molecular docking studies which prove that the binding modes of Ceritinib and Nicotinamide gave prominent binding scores and interaction with active site amino acids. Finally, it could be concluded that the cocrystals of ceritinib by dry grinding technique improved the solubility. Therefore cocrystals formation by dry grinding technique might be a useful strategy for increasing the therapeutic potential of ceritinib. Hence cocrystallization is an important technique to enhance the solubility of poorly soluble drugs. 
RASĀYAN J. Chem.

Vol. 14 | No. 2 |905-913| April - June | 2021

\section{ACKNOWLEDGEMENT}

The author would like to thank Manipal College of Pharmaceutical Science and Manipal Academy of Higher Education, Manipal for providing the materials and resources to carry out this work.

\section{REFERENCES}

1. R. Chennuru, T. Koya, P. Kommavarapu, S.V. Narasayya, P. Muthudoss, P. Vishweshwar, R. Ravi Chandra Babu, S. Mahapatra, Crystal Growth and Design, 17(12), 6341(2017), DOI:10.1021/acs.cgd.7b01027

2. Certinib Formulation which is Patented with the Publication Number US 2017/0112834 A1 dt on. Apr 27, 2017 by Novartis AG, Basel (CH), https://patentimages.storage.googleapis.com/b5/91/6b/ 64b7d97742eac9/US20170112834A1.pdf

3. D.P. Konakanchi, S. R. Pula, M. B. Pallooru, R. R. Samatham, R. Pilli, L. V. V. P. K. Maddula, V.C. Nannapaneni, U.S. Patent No. 10,604,505, Washington, DC: U.S. Patent and Trademark Office. (2020).

4. U. Kotak, V.Prajapati, H. Solanki, G. Jani, P. Jha, World Journal Pharmacy and Pharmaceutical Science, 4(4), 1484(2015).

5. B.S. Sekhon, ARS Pharmaceutica, 5(2), 99(2009).

6. A.V. Yadav, A. S. Shete, A. P. Dabke, P.V. Kulkarni, S.S. Sakhare, Indian Journal of Pharmaceutical Sciences, 71(4), 359(2009), DOI:10.4103/0250-474X.57283

7. D.D.Gadade, S. S. Pekamwar, Advanced Pharmaceutical Bulletin, 6(4), 479(2016), DOI: 10.15171/apb.2016.062

8. N. Schultheiss, A. Newman, Crystal Growth and Design, 9(6), 2950 (2009), DOI:10.1021/cg900129f

9. National Center for Biotechnology Information. PubChem Database Ceritinib, (2020) https://pubchem.ncbi.nlm.nih.gov/compound/57379345

10. National Center for Biotechnology Information. PubChem Database, Quercetin Hydrate(2020), https://pubchem.ncbi.nlm.nih.gov/compound/5284452

11. National Center for Biotechnology Information. PubChem Database, Nicotinamide(2020) https://pubchem.ncbi.nlm.nih.gov/compound/936)

12. J. Wouters and L. Quéré(Eds.), Royal Society of Chemistry, pp. 9-28(2011), DOI: $10.1039 / 9781849733502$

13. C. N. Kumar, V. Prathyusha, N. A. Kannappan, Der Pharmacia Lettre, 6(5),339 (2014).

14. V. S. Adhao, J. Sharma, M. Thakre, Indonesian Journal of Pharmacy, 28(4), 241(2018), DOI: 10.14499/indonesianjpharm28iss4pp241

15. S. Kapavarapu, N. Mopidevi, R. Chintala, Asian Journal of Pharmaceutical and Clinical Research. 8, 44(2015).

16. Small-Molecule Drug Discovery Suite 2016-3 Glide, Version 7.2, Schrödinger, LLC, New York, NY, (2016).

[RJC-6244/2020] 